\title{
Enhanced Combined Tomography and Biomechanics Data for Distinguishing Forme Fruste Keratoconus
}

\author{
Allan Luz, MD; Bernardo Lopes, MD; Katie M. Hallahan, MD; Bruno Valbon, MD; Isaac Ramos, MD; \\ Fernando Faria-Correia, MD; Paulo Schor, MD, PhD; William J. Dupps, Jr., MD, PhD; \\ Renato Ambrósio, Jr., MD, PhD
}

\section{ABSTRACT}

PURPOSE: To evaluate the performance of the Ocular Response Analyzer (ORA) (Reichert Ophthalmic Instruments, Depew, NY) variables and Pentacam HR (Oculus Optikgeräte $\mathrm{GmbH}$, Wetzlar, Germany) tomographic parameters in differentiating forme fruste keratoconus (FFKC) from normal corneas, and to assess a combined biomechanical and tomographic parameter to improve outcomes.

METHODS: Seventy-six eyes of 76 normal patients and 21 eyes of 21 patients with FFKC were included in the study. Fifteen variables were derived from exported ORA signals to characterize putative indicators of biomechanical behavior and 37 ORA waveform parameters were tested. Sixteen tomographic parameters from Pentacam HR were tested. Logistic regression was used to produce a combined biomechanical and tomography linear model. Differences between groups were assessed by the Mann-Whitney $U$ test. The area under the receiver operating characteristics curve (AUROC) was used to compare diagnostic performance.

RESULTS: No statistically significant differences were found in age, thinnest point, central corneal thickness, and maximum keratometry between groups. Twenty-one parameters showed significant differences between the FFKC and control groups. Among the ORA waveform measurements, the best parameters were those related to the area under the first peak, p1area1 (AUROC, $0.717 \pm 0.065)$. Among the investigator ORA variables, a measure incorporating the pressure-deformation relationship of the entire response cycle was the best predictor (hysteresis loop area, AUROC, $0.688 \pm 0.068$ ). Among tomographic parameters, Belin/Ambrósio display showed the highest predictive value (AUROC, $0.91 \pm$ 0.057 ). A combination of parameters showed the best result (AUROC, $0.953 \pm 0.024$ ) outperforming individual parameters.

CONCLUSIONS: Tomographic and biomechanical parameters demonstrated the ability to differentiate FFKC from normal eyes. A combination of both types of information further improved predictive value.

[J Refract Surg. 2016;32(7):479-485.]

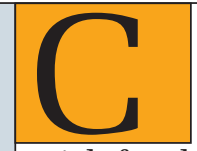

orneal ectasia is one of the most feared complications of keratorefractive surgery, and there is interest in the preoperative identification of patients at risk for developing it. ${ }^{1}$ Preoperative Placido disk-based topographic abnormalities for natural ectatic conditions, such as keratoconus, are considered the most important risk factor. ${ }^{2}$ Despite well-defined clinical signs, the early forms of the disease present diagnostic challenges. The term "forme fruste keratoconus" (FFKC) refers to topographic patterns that are insufficient to reach the threshold of keratoconus based on computed quantitative indices. ${ }^{3}$

Recent advances in anterior segment tomography, based on Scheimpflug technology, have provided a variety of quantitative indices, such as detailed corneal pachymetry and elevation maps., ${ }^{4,5}$ Studies have demonstrated that they can provide useful information in refractive screening. ${ }^{6}$ Additionally, a panel of candidate diagnostic variables using exported Ocular Response Analyzer (ORA) (version 2.04; Reichert Ophthalmic Instruments, Depew, NY) data to characterize the temporal, applanation signal intensity, and pressure features of the corneal response demonstrated the ability to distinguish keratoconus from normal corneas more accu-

From the Department of Ophthalmology of the Federal University of São Paulo, São Paulo, Brazil (AL, PS, RA); Cole Eye Institute, Cleveland Clinic, Cleveland, Ohio (KMH, WJD); Biomedical Engineering, Cleveland Clinic Lerner Research Institute, Cleveland, Ohio (KMH, WJD); the Department of Ophthalmology of the University of São Paulo, São Paulo, Brazil (BV); Cornea and Refractive Surgery Department, Hospital de Olhos de Sergipe, Aracaju, Brazil (AL); Cornea and Refractive Surgery Department, Hospital de Braga, Braga, Portugal (FF-C); Rio de Janeiro Corneal Tomography and Biomechanics Study Group (AL, BL, BV, IR, FF-C, RA), Rio de Janeiro, Brazil; and Instituto de Olhos Renato Ambrósio and Visare Personal Laser, Rio de Janeiro, Brazil (BL, BV, RA).

Submitted: August 21, 2015; Accepted: March 17, 2016

Supported in part by NIH R01EY023381 (WJD).

Dr. Ambrósio is a consultant for Oculus Optikgeräte GmbH (Wetzlar, Germany). Dr. Dupps has intellectual property issued through Cleveland Clinic Innovations for a technique for biomechanical measurement that is not addressed in this article, is a consultant for Ziemer, and is on the sponsored research and medical advisory board for Avedro. The remaining authors have no financial or proprietary interest in the materials presented herein.

Correspondence: Allan Luz, MD, Jorge Amado Avenue, 1500 - Jardins - 49025 330 Aracaju, SE - Brazil. E-mail: dr.allanluz@gmail.com

doi:10.3928/1081597X-20160502-02 
rately than some original pressure-derived parameters ${ }^{7}$ (corneal hysteresis $[\mathrm{CH}]$ and corneal resistance factor [CRF]).

The purpose of this study was to evaluate the diagnostic capacity of tomographic parameters, ORA biomechanical variables (including novel waveform-derived variables related to pressure, applanation signal intensity, response time, and combinations of these variables), and a combination model in differentiating FFKC from normal corneas.

\section{PATIENTS AND METHODS}

This study was a comparative, observational, retrospective, non-interventional case series. It was approved by the Ethics and Research Committee of São Paulo Federal University (Protocol 2012/10) and followed the tenets of the Declaration of Helsinki.

Patients were examined at the Instituto de Olhos Renato Ambrósio (Rio de Janeiro, Brazil). We studied 97 eyes of 97 patients who were divided into two groups: the FFKC group, comprising 21 eyes of 21 patients with normal Placido-disk corneal topographies and in whom the fellow eye had keratoconus, and the control group, comprising 76 eyes of 76 patients with bilateral normal corneas (Figure A, Figure B, and Figure C, available in the online version of this article). The control group was formed by randomly choosing a single eye of patients with bilaterally normal eyes according to topographic criteria.

The criteria of normality and disease were based on the Rabinowitz indices and were evaluated by a corneal topographer using Placido disks (Atlas 9000; Carl Zeiss Meditec, Jena, Germany). A KISA index greater than $100 \%$ was considered early keratoconus, less than $60 \%$ was considered normal, and $60 \%$ to $100 \%$ was considered suspected keratoconus. ${ }^{8}$ The fellow eye was considered for analysis when the KISA index on corneal topography was less than $60 \%$ without a suspect pattern.

The control group included patients without corneal topographic irregularities, high refractive error, or collagen vascular disease. Excluded from both groups were patients with severe atopic keratoconjunctivitis, ${ }^{9}$ a history of ocular surgery or any eye disease, except for keratoconus in the fellow eye of patients with FFKC, or any systemic disease or syndrome.

A comprehensive eye examination was conducted for all patients. In addition to topographic data, the following information was obtained for each patient: age, thinnest point, central corneal thickness, topographic astigmatism, and maximum keratometry (Kmax). Biomechanical data were obtained with the ORA and included the Goldmann-correlated intraocular pressure (IOPg), corneal compensated intraocular pressure (IOPcc), CH,
CRF, 37 parameters derived from analyses of the waveform signal, ${ }^{10}$ and 15 custom variables proposed in this article using exported ORA data to characterize the temporal, applanation signal intensity, and pressure features of the corneal response. Additionally, 16 tomographic parameters from the Pentacam HR Scheimpflug tomography system (Oculus Optikgeräte GmbH, Wetzlar, Germany) were tested. The following were derived from the corneal surface: index surface variance, index of vertical asymmetry, and index of height decentration. The following were derived from elevation: enhanced best fit sphere (BFS) front, enhanced BFS back, elevation B BFS Apex, elevation B BFS Thinnest, elevation B BFS Max 4-mm Zone, elevation B best fit toric ellipsoid (BFTE) Apex, elevation B BFTE Thinnest, and elevation B BFTE Max 4-mm Zone. The following were derived from pachymetry: Belin/Ambrósio display (BAD-D), Ambrósio relational thickness (ART) Max, ART Average, relative pachymetric increase (RPI) Max, and RPI Average. Elevation data were taken from a fixed 8-mm zone (BFS set to manual, float, sphere, diameter $8 \mathrm{~mm}$ ) centered on the corneal apex. All tomographic variables and their interpretations are described in Table A (available in the online version of this article).

ORA infrared intensity and pressure time series data were exported using ORA software and analyzed using custom Matlab routines (version 7.0; MathWorks, Natick, MA) as described previously. ${ }^{7}$ Briefly, 15 variables were derived from the ORA signal and grouped according to waveform features: applanation signal intensity (group 1), applied pressure (group 2), time (group 3), the applanation signal intensity as a function of response time (group 4), the relationship between applied pressure and the applanation signal response (group 5), and the relationship between pressure and time (group 6). All variables and their interpretations are described in Table B (available in the online version of this article). These investigatorderived variables defined features from the ORA signal are hypothesized to be biomechanically relevant ${ }^{7}$; they are introduced in Figure 1.

The ORA calculates a waveform score that is used to select the best quality measurement value of each parameter. ${ }^{11}$ We used the examination with the best waveform score (ie, the best quality measurement) after four consecutive measurements. All ORA and Pentacam data were obtained by the same experienced operator (BV) in a consistent way during office hours.

Statistical analyses were performed using BioEstat 5.0 (Mamirauá Institute, Amazonas, Brazil) and MedCalc 11.1 (MedCalc Software, Mariakerke, Belgium) software. The non-parametric Mann-Whitney $U$ test (Wilcoxon rank sum) was used to evaluate the distribu- 
tion of variables between the two groups. The significance criterion was subjected to Bonferroni correction.

The receiver operating characteristics (ROC) curve and the area under the ROC curve (AUROC) were calculated for each parameter to examine differences between the groups and determine the overall predictive accuracy of each test. The standard error of the AUROC was evaluated using the method of DeLong et al. ${ }^{12}$ The exact binomial method was used to calculate confidence intervals for AUROCs, with 0.700 indicating the cut-off point for poor parameter performance. ${ }^{10}$ Nonparametric pair-wise comparisons of the ROC curves were performed to test whether significant differences were present in the areas for each parameter using the Hanley-McNeil method for calculating the standard error. ${ }^{13,14} P$ values less than .05 were considered statistically significant. The results are expressed as AUROC, sensitivity, and specificity. In Table $\mathbf{C}$ (available in the online version of this article), the AUROC, $P$ value, sensitivity, specificity, confidence interval, standard error, and cut-off values are presented.

Furthermore, step-wise logistic regression analysis $^{15}$ was performed to combine the best variables from ORA-derived biomechanical properties and Pentacamderived tomographic parameters to determine the predictive capability (function-enhanced combined tomography and biomechanics [FECTB]). Based on the control and FFKC groups, the discriminant analysis resulted in a linear function of the variables:

$$
\mathrm{L}=\mathrm{b}_{1} \mathrm{x}_{1}+\mathrm{b}_{2} \mathrm{x}_{2}+\mathrm{b}_{\mathrm{n}} \mathrm{x}_{\mathrm{n}}+\mathrm{c}
$$

where $\mathrm{b}$ is a discriminant coefficient, $\mathrm{x}$ is an input variable, and $\mathrm{c}$ is a constant.

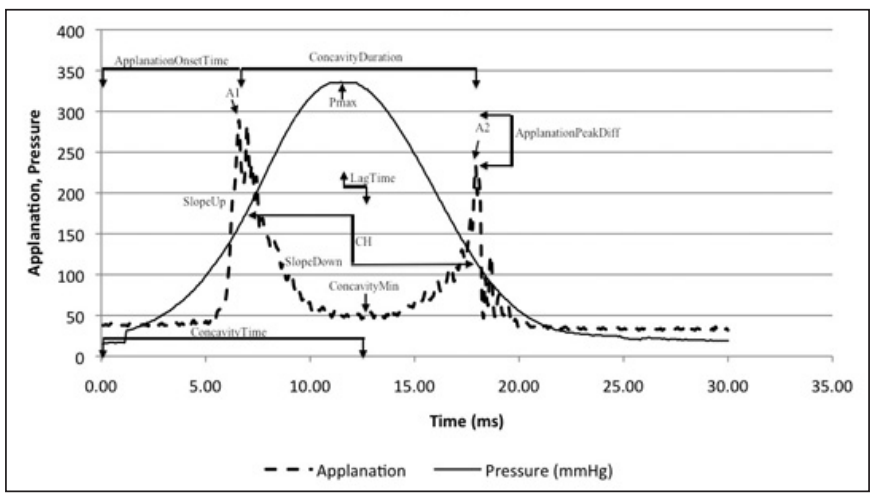

Figure 1. Ocular Response Analyzer (ORA) (Reichert Ophthalmic Instruments, Depew, NY) signal output with select variables from applanation signal intensity (A1, A2, Applanation peak difference, and Concavity min); pressure (Pmax); time (concavity duration, concavity time, and lag time); applanation signal intensity as a function of response time (slope up and slope down). $\mathrm{CH}=$ corneal hysteresis

\section{RESULTS}

Table 1 summarizes the demographic, IOP, and topographic and tomographic characteristics of each group. Mean central pachymetry, thinnest point of the cornea, age, IOPg, IOPcc, astigmatism, and Kmax were not significantly different between the groups $(P>.05)$. The mean KISA index was $17.87 \%$ in the FFKC group and $11.57 \%$ in the control group $(P=.049)$.

Table D (available in the online version of this article) compares the biomechanical parameters of the groups. Eleven parameters differed significantly between the groups: $\operatorname{Pmax}(P=.391)$, hysteresis loop area (HLA) $(P=.0086)$, Impulse $(P=.0363)$, p1area $(P=$ $.0037)$, dive1 $(P=.0375)$, h1 $(P=.0228)$, p1area1 $(P=$ $.0024)$, h11 $(P=.0228)$, uslope2 $(P=.0478)$, mslew2 $(P$ $=.0421)$, and slew2 $(P=.0487)$ (Table 2). Neither $\mathrm{CH}$ nor CRF showed a statistically significant difference.

TABLE 1

Comparison of Characteristics and Intraocular Pressure

\begin{tabular}{|c|c|c|c|}
\hline Characteristic & FFKC Group Mean \pm SD (Range) & Control Group Mean \pm SD (Range) & $P^{\mathbf{a}}$ \\
\hline Patients & 21 & 76 & - \\
\hline Eyes & 21 & 76 & - \\
\hline Age $(y)$ & $25.5 \pm 7.2(14.9$ to 48.5$)$ & $25.7 \pm 5.2(12.5$ to 38.8$)$ & .50 \\
\hline Central pachymetry $(\mu \mathrm{m})$ & $527.3 \pm 16.7$ (477 to 576$)$ & $530 \pm 26.3$ (458 to 632$)$ & .05 \\
\hline Thinnest point $(\mu \mathrm{m})$ & $526 \pm 16.9$ (474 to 566$)$ & $527.4 \pm 26$ (457 to 629$)$ & .10 \\
\hline Astigmatism (D) & $1.20 \pm 0.80(0.20$ to 3.40$)$ & $1.50 \pm 1.10(0.10$ to 5.30$)$ & .30 \\
\hline Kmax (D) & $44.90 \pm 1.80$ (42.30 to 48.40$)$ & $44.40 \pm 1.40$ (400 to 47.70 ) & .50 \\
\hline IOPg (mm Hg) & $12.5 \pm 2.8(8.4$ to 17.2$)$ & $13.8 \pm 2.9(7.9$ to 20$)$ & .10 \\
\hline IOPcc (mm Hg) & $14.3 \pm 3.4(9.9$ to 21$)$ & $14.8 \pm 2.6(7.6$ to 21.7$)$ & .30 \\
\hline
\end{tabular}

FFKC = forme fruste keratoconus; $S D=$ standard deviation; $D=$ diopters; Kmax = maximum keratometry; IOPg = Goldmann intraocular pressure; IOPcC = corneal compensate intraocular pressure

aMann-Whitney $U$ test. 


\section{TABLE 2}

Comparison of ORA Variables With the Best 11 Parameters Differing Significantly Between the Groups

\begin{tabular}{|c|c|c|c|}
\hline Parameter & Normal Mean \pm SD (Range) & FFKC Mean \pm SD (Range) & $p^{a}$ \\
\hline p1area1 & $1,412.29 \pm 447.54(554.25$ to $2,686.5)$ & $1,085.19 \pm 363.43(553.5$ to $1,762.38)$ & $.0024^{b}$ \\
\hline p1area & $3,331.25 \pm 910.23(1,402$ to $5,606.06)$ & $2,644.83 \pm 746.93(1,450.13$ to 4,008$)$ & $.0037^{\mathrm{b}}$ \\
\hline h1 & $377.05 \pm 103.64(218.62$ to 640.87$)$ & $319.06 \pm 102.74$ (168.75 to 563.62$)$ & $.0228^{b}$ \\
\hline h11 & $251.37 \pm 69.09$ (145.75 to 427.25$)$ & $212.70 \pm 68.49(112.5$ to 375.35$)$ & $.0228^{b}$ \\
\hline dive1 & $323.77 \pm 117.79$ (38.75 to 614.5$)$ & $266.39 \pm 115.82(19.5$ to 561.75$)$ & .0375 \\
\hline Pmax & $423.74 \pm 35.49$ (344 to 505$)$ & $408.43 \pm 45.09$ (348 to 557$)$ & .0391 \\
\hline mslew2 & $127.75 \pm 56.57$ (25.75 to 326$)$ & $97.08 \pm 51.35(19.25$ to 173$)$ & .0421 \\
\hline uslope2 & $85.99 \pm 43.24$ (14.67 to 239.12$)$ & $62.14 \pm 45.55(3.27$ to 138.75$)$ & .0478 \\
\hline slew2 & $86.40 \pm 42.63$ (17.5 to 239.12$)$ & $63.70 \pm 44.10(6.66$ to 138.75$)$ & .0487 \\
\hline
\end{tabular}

\begin{tabular}{|c|c|c|c|}
\hline \multicolumn{4}{|c|}{$\begin{array}{c}\text { TABLE } 3 \\
\text { Comparison of Tomographic Parameters for Normal and FFKC Groups }\end{array}$} \\
\hline Parameter & Normal Group Mean \pm SD (Range) & FFKC Group Mean \pm SD (Range) & $P^{\mathbf{a}}$ \\
\hline BAD-D & $0.52 \pm 0.50(-0.68$ to 1.34$)$ & $1.84 \pm 1.34(-0.22$ to 7$)$ & $<.0001^{\mathrm{b}}$ \\
\hline ART Maximum & $497.90 \pm 72.82(403$ to 663$)$ & $379.80 \pm 88.49$ (250 to 593 ) & $<.0001^{\mathrm{b}}$ \\
\hline ART Average & $608.11 \pm 78.86$ (486 to 807 ) & $495.04 \pm 89.09$ (329 to 718$)$ & $<.0001^{\mathrm{b}}$ \\
\hline Elevation B BFS 8-mm Thinnest & $1.52 \pm 3.10((-3$ to 9$)$ & $7.47 \pm .5 .65(-5$ to 18$)$ & $<.0001^{\mathrm{b}}$ \\
\hline Elevation B BFTE 8-mm Thinnest & $-1.44 \pm 2.83(-7$ to 7$)$ & $3.95 \pm 4.89(-8$ to 14$)$ & $<.0001^{\mathrm{b}}$ \\
\hline Elevation B BFTE 8-mm Max 4-mm Zone & $6.81 \pm 2.01(4$ to 13$)$ & $9.57 \pm 3.20(18$ to 4$)$ & $<.0001^{\mathrm{b}}$ \\
\hline RPI Maximum & $1.05 \pm 0.16(0.82$ to 1.36$)$ & $1.41 \pm 0.28(0.91$ to 1.94$)$ & $<.0001^{\mathrm{b}}$ \\
\hline RPI Average & $0.87 \pm 0.10(0.68$ to 1.04$)$ & $1.03 \pm 0.16(0.73$ to 1.47$)$ & $<.0001^{\mathrm{b}}$ \\
\hline Enhanced BFS Front $8 \mathrm{~mm}$ & $7.93 \pm 0.22(7.38$ to 8.57$)$ & $7.81 \pm 0.20(7.44$ to 8.1$)$ & .0413 \\
\hline Elevation B BFTE 8-mm Apex & $-1.31 \pm 3.14(-8$ to 8$)$ & $0.80 \pm 4.47(-7$ to 11$)$ & .043 \\
\hline Enhanced BFS Back 8 mm & $6.57 \pm 0.22(5.97$ to 7.17$)$ & $6.47 \pm 0.23(6.05$ to 6.86$)$ & .1232 \\
\hline IHD & $3.60 \pm 2.28(0.001$ to 8$)$ & $4.85 \pm 3.07(0.001$ to 8$)$ & .1677 \\
\hline Elevation B BFS 8-mm Apex & $0.78 \pm 2.28(-3$ to 9$)$ & $2.23 \pm 4.04(-4$ to 13$)$ & .2217 \\
\hline ISV & $21.32 \pm 7.42(46$ to 8$)$ & $19.33 \pm 5.23(10$ to 31$)$ & .446 \\
\hline Elevation B BFS 8-mm Max 4-mm Zone & $13.53 \pm 4.63$ (4 to 26$)$ & $14.52 \pm 4.94$ (7 to 27$)$ & .4539 \\
\hline IVA & $0.37 \pm 1.179(0.04$ to 7$)$ & $0.16 \pm 0.06(0.09$ to 0.3$)$ & .6456 \\
\hline
\end{tabular}

Table 3 compares the tomographic parameters of groups. Ten of 16 parameters differed significantly between the groups: BAD-D $(P<.0001)$, ART Max $(P<$ .0001), ART Avg $(P<.0001)$, enhanced BFS front $(P=$ .0413), elevation B BFS Thinnest $(P<.0001)$, elevation
B BFTE Apex $(P=.043)$, elevation B BFTE Thinnest $(P<.0001)$, elevation B BFTE Max 4 -mm Zone $(P<$ .0001), and RPI Max and RPI avg $(P<.0001)$.

Results of ROC analysis showed that the five best-performing variables, determined by the highest AUROC 
values, were BAD-D (AUROC, 0.91), Elevation B BFTE Thinnest (AUROC, 0.872), ART Max (AUROC, 0.863), RPI Max (AUROC, 0.841), and Elevation B BFS Thinnest (AUROC, 0.0839). BAD-D, Elevation B BFTE Thinnest, and ART Max showed sensitivities of 90.48\%, 85.71\%, and $85.71 \%$ and specificities of $82.89 \%, 78.95 \%$, and $78.95 \%$, respectively (Table C).

Moreover, the highest AUROC was found for the logistic regression model. Sensitivity was $85.71 \%$, specificity was $98.68 \%$, and the AUROC was 0.953 . The regression was expressed by the following formula:

$1.167 \times$ BAD-D $-0.003 \times$ ART Max $-1.758 \times$ Enhanced BFS Front $+0.141 \times$ Elevation B BFTE Thinnest $+0.492 \times$ Elevation B BFTE Max 4-mm Zone - $0.017 \times$ Pmax -3.505 $\times$ HLA $-2.705 \times$ p1area $-0.002 \times$ dive $1-0.020 \times$ slew 2

Additionally, Figure 2 shows the AUROCs of FECTB, p1area1, and BAD-D. These parameters were the best from each group (tomography and biomechanics).

\section{DISCUSSION}

The diagnostic approach for FFKC has improved in recent years, mainly due to contemporary anterior segment imaging technologies. Indices such as the ART and BAD-D facilitate the identification of corneal abnormalities. ${ }^{1,5,16}$ Our study used these indices and others related to the elevation and pachymetry distribution to discriminate FFKC from normal corneas. Additionally, this study provides insight into differences in the dynamic behavior of FFKC and normal eyes through analysis of novel waveform-derived candidate variables related to pressure, applanation, response time, or a combination of these variables. ${ }^{7}$

Our study suggests that a combined tomography and biomechanical approach can enhance screening for FFKC. Although tomographic findings have shown better overall results, it was by combining them with biomechanical data that we determined the best AUROC to discriminate between the two groups. Taking into account that our groups are matched for thinnest point, Kmax, age, and central pachymetry values, there is no index in the "classic" screening that distinguishes between the two populations, and the differences found were derived from intrinsic characteristics of the cornea. ${ }^{17}$

FFKC shows (1) marked reductions in a comprehensive hysteresis analog (HLA) that captures the pressure deformation behavior of the entire response cycle, (2) reduction in the force and time required to reach initial applanation, (3) lower maximum air pressure intensity required to produce applanation as a function of a peak pressure and time, (4) reduced area under the initial applanation intensity curve, (5) no difference in

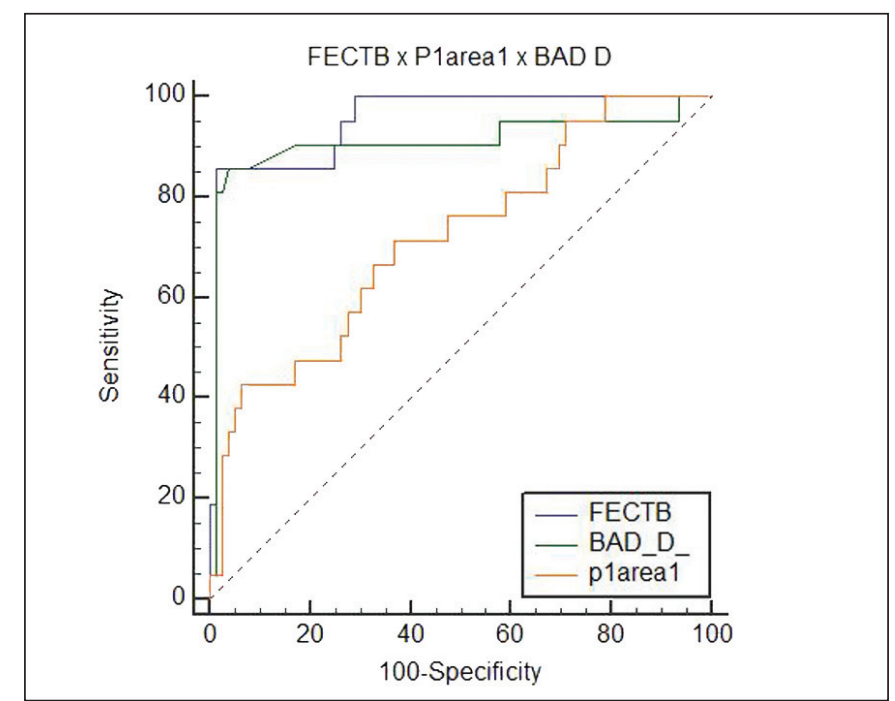

Figure 2. Receiver operating characteristic curves for function-enhanced combined tomography and biomechanics (FECTB), P1area1, and Belin/ Ambrósio display (BAD_D).

high-frequency oscillation in regions between peaks and no difference from normal in corneal deformation after a puff, and (6) lower speed of corneal deformation after applanation. Likewise, parameters of pachymetry and elevation, such as BAD-D and ART Max, showed excellent results. These results suggest that FFKC is characterized by a modification of the cornea's shape and thickness. The highlight of the parameters derived from the back elevation at the thinnest point is BFTE or BFS, the AUROCs of which were 0.87 and 0.83 , respectively, suggesting that an increase in posterior elevation concomitant to corneal thinning may be an important sign of FFKC. ${ }^{18}$

According to a previous study that assessed FFKC with Orbscan data, posterior elevation and corneal thickness indices may be the most useful parameters to discriminate between the FFKC and normal groups. The same study suggested that Placido disk-based indices were not sufficient to detect the earliest form of keratoconus. ${ }^{18}$ Another study using the Pentacam, similar to our study, showed corneal thickness distribution and posterior elevation to be more helpful than anterior curvature data in identifying eyes with subclinical keratoconus. ${ }^{19}$ As described previously, corneal thickness at the thinnest point, corneal thickness spatial profile, and percentage of thickness increase are known discriminant indices between keratoconus and normal. ${ }^{4}$ Furthermore, ART values were shown to be better than single-point pachymetric parameters for discriminating normal eyes from keratoconic eyes. ${ }^{5}$ A previous study found that anterior curvature data had a higher discriminant ability than elevation or pachymetric parameters, but this difference may be ex- 
plained by differing methodologies, where FFKC was defined not with normal anterior curvature but with elevation and pachymetry using the BAD-D. ${ }^{20}$

Regarding the biomechanical indices, our results demonstrated that $\mathrm{CH}$ and $\mathrm{CRF}$ were not capable of discriminating FFKC ( $P=.13$ and .08 , respectively). A previous study differed from this, ${ }^{21}$ probably because our group was more restrictive in morphological properties, being matched for thinnest point, Kmax, central pachymetry, and age. Our findings confirm prior results showing that maximum applied pressure levels were significantly different between FFKC and normal eyes, with lower values for FFKC. ${ }^{17}$ In a previous study comparing the same custom variables in keratoconic and normal eyes, all variables except lag time were significantly different, and the concavity min and HLA showed the greatest discriminant value for keratoconus. ${ }^{7}$ In the current study, HLA showed an AUROC of 0.688 (sensitivity $61.90 \%$, specificity $61.84 \%$ ) and was the best discriminant custom variable.

The concern that IOP differences could confound the predictive value of key variables in the current study was minimized due to absence of statistically significant IOPg or IOPcc differences between groups. Moreover, although the difference between the two groups was statistically significant $(P=.049)$, KISA index values were far below the $60 \%$ threshold for classification as suspected keratoconus based on anterior topography features alone. ${ }^{8}$

Among all of the biomechanical parameters, those that showed the best outcomes were p1area and p1area1 (AUROC 0.707 and 0.717 , respectively). A previous study also highlighted p1area, p1area1, p2area, and p2area1 for their performance in identifying grades I and II keratoconus. ${ }^{22}$ By contrast, the current study demonstrated only that areas related to the first applanation event were significant in FFKC. Low values of $\mathrm{p} 1$ and $\mathrm{p} 2$ represent rapid applanation or applanation-recovery responses that are consistent with less viscous damping, but may also reflect reduced applanation signal intensities due to complex corneal surface deformation responses, driven by corneal material property inhomogeneities. Because the applanation signal height variables were significantly lower in the FFKC group in this study and the width was not significantly different, it seems likely that the lower mean applanation signal height was the driver of lower p1area in the FFKC group.

The main clinical importance of our findings is that a combination of parameters, biomechanical and tomographic, can achieve better results than the cited variables studied individually. Unlike other studies that studied only traditional CH and CRF, our study goes further and presents a wide range of biomechanical data beyond $\mathrm{CH}$ and CRF. Although elevation and pachymetric indices achieved better individual AUROC values when studied independently (BAD-D AUROC, 0.91 and ART Max AUROC, 0.863), the best outcome can be achieved with the introduction of biomechanical data (FECTB AUROC, 0.953).

Some characteristics and limitations of our study should be considered. First, our study is limited by the small number of participants in the FFKC group. Second, this study was an exploratory analysis designed to restrict the initial number of candidate variables to a smaller subset of promising variables. Third, other tomographic findings, such as corneal volume, were not studied because they have been shown not to undergo significant changes in the early stages of the disease. ${ }^{23}$

Pentacam HR tomographic parameters and ORA biomechanical custom variables can be useful in diagnosing FFKC. A combination of both types of information further improved the predictive value. Additional research on these models will contribute to validating software that may help the clinician in detecting susceptibility to corneal ectasia.

\section{AUTHOR CONTRIBUTIONS}

Study concept and design (AL, KMH, PS, WJD, RA); data collection ( $A L, B L, B V, I R, F F-C$ ); analysis and interpretation of data ( $A L$, $K M H, W J D, R A)$; writing the manuscript ( $A L, B L, B V, I R, F F-C, P S$ ); critical revision of the manuscript ( $K M H, W J D, R A)$; statistical analysis (BL); supervision (WJD, RA)

\section{REFERENCES}

1. Binder PS, Trattler WB. Evaluation of a risk factor scoring system for corneal ectasia after LASIK in eyes with normal topography. J Refract Surg. 2010;26:241-250.

2. Randleman JB, Trattler WB, Stulting RD. Validation of the Ectasia Risk Score System for preoperative laser in situ keratomileusis screening. Am J Ophthalmol. 2008;145:813-818.

3. Klyce SD. Chasing the suspect: keratoconus. Br J Ophthalmol. 2009;93:845-847.

4. Ambrósio R Jr, Alonso RS, Luz A, Coca Velarde LG. Cornealthickness spatial profile and corneal-volume distribution: tomographic indices to detect keratoconus. J Cataract Refract Surg. 2006;32:1851-1859.

5. Ambrósio R Jr, Caiado AL, Guerra FP, et al. Novel pachymetric parameters based on corneal tomography for diagnosing keratoconus. J Refract Surg. 2011;27:753-758.

6. Belin MW, Villavicencio OF, Ambrósio RR Jr. Tomographic parameters for the detection of keratoconus: suggestions for screening and treatment parameters. Eye Contact Lens. 2014;40:326-330.

7. Hallahan KM, Sinha Roy A, Ambrósio R Jr, Salomao M, Dupps WJ Jr. Discriminant value of custom ocular response analyzer waveform derivatives in keratoconus. Ophthalmology. 2014;121:459-468. 
8. Rabinowitz YS, Rasheed K. KISA\% index: a quantitative videokeratography algorithm embodying minimal topographic criteria for diagnosing keratoconus. J Cataract Refract Surg. 1999;25:1327-1335.

9. Ibrahim OM, Dogru M, Kaido M, Kojima T, Fujishima H, Tsubota K. Functional visual acuity assessment of severe atopic keratoconjunctivitis. Cornea. 2014;33(suppl 11):S13-S18.

10. Mikielewicz M, Kotliar K, Barraquer RI, Michael R. Air-pulse corneal applanation signal curve parameters for the characterisation of keratoconus. Br J Ophthalmol. 2011;95:793-798.

11. Luz A, Fontes BM, Lopes B, Ramos I, et al. Best waveform score for diagnosing keratoconus. Revista Brasileira de Oftalmologia. 2013;72:361-365.

12. DeLong ER, DeLong DM, Clarke-Pearson DL. Comparing the areas under two or more correlated receiver operating characteristic curves: a nonparametric approach. Biometrics. 1988;44:837845.

13. McNeil BJ, Hanley JA. Statistical approaches to the analysis of receiver operating characteristic (ROC) curves. Med Decis Making. 1984;4:137-150.

14. McNeil BJ, Kirkwood JR, Hanley JA, Polak J, Wilkinson R, Funkenstein HH. Computed tomographic studies of the head in a teaching hospital and a community hospital: a comparison. Radiology. 1982;145:367-370.

15. Hosmer DW Jr, Lemeshow S. Applied Logistic Regression, 2nd ed. New York: John Wiley \& Sons; 2000.

16. Ambrósio R Jr, Ramos I, Lopes B, et al. Assessing ectasia susceptibility prior to LASIK: the role of age and residual stromal bed (RSB) in conjunction to Belin-Ambrósio deviation index (BAD-D). Revista Brasileira de Oftalmologia. 2014;73:75-80.

17. Schweitzer C, Roberts CJ, Mahmoud AM, Colin J, Maurice-Tison S, Kerautret J. Screening of forme fruste keratoconus with the Ocular Response Analyzer. Invest Ophthalmol Vis Sci. 2010;51:2403-2410.

18. Saad A, Gatinel D. Topographic and tomographic properties of forme fruste keratoconus corneas. Invest Ophthalmol Vis Sci. 2010;51:5546-5555.

19. Uçakhan ÖÖ, Cetinkor V, Özkan M, Kanpolat A. Evaluation of Scheimpflug imaging parameters in subclinical keratoconus, keratoconus, and normal eyes. J Cataract Refract Surg. 2011;37:11161124.

20. Bae GH, Kim JR, Kim CH, Lim DH, Chung ES, Chung TY. Corneal topographic and tomographic analysis of fellow eyes in unilateral keratoconus patients using Pentacam. Am J Ophthalmol. 2014;157:103-109.

21. Kozobolis V, Sideroudi H, Giarmoukakis A, Gkika M, Labiris G. Corneal biomechanical properties and anterior segment parameters in forme fruste keratoconus. Eur J Ophthalmol. 2012;22:920-930

22. Ventura BV, Machado AP, Ambrósio R Jr, et al. Analysis of waveform-derived ORA parameters in early forms of keratoconus and normal corneas. J Refract Surg. 2013;29:637-643.

23. Piñero DP, Alió JL, Alesón A, Escaf Vergara M, Miranda M. Corneal volume, pachymetry, and correlation of anterior and posterior corneal shape in subclinical and different stages of clinical keratoconus. J Cataract Refract Surg. 2010;36:814-825. 


\section{OCULUS - PENTACAM Show 2 Exams Topometric}

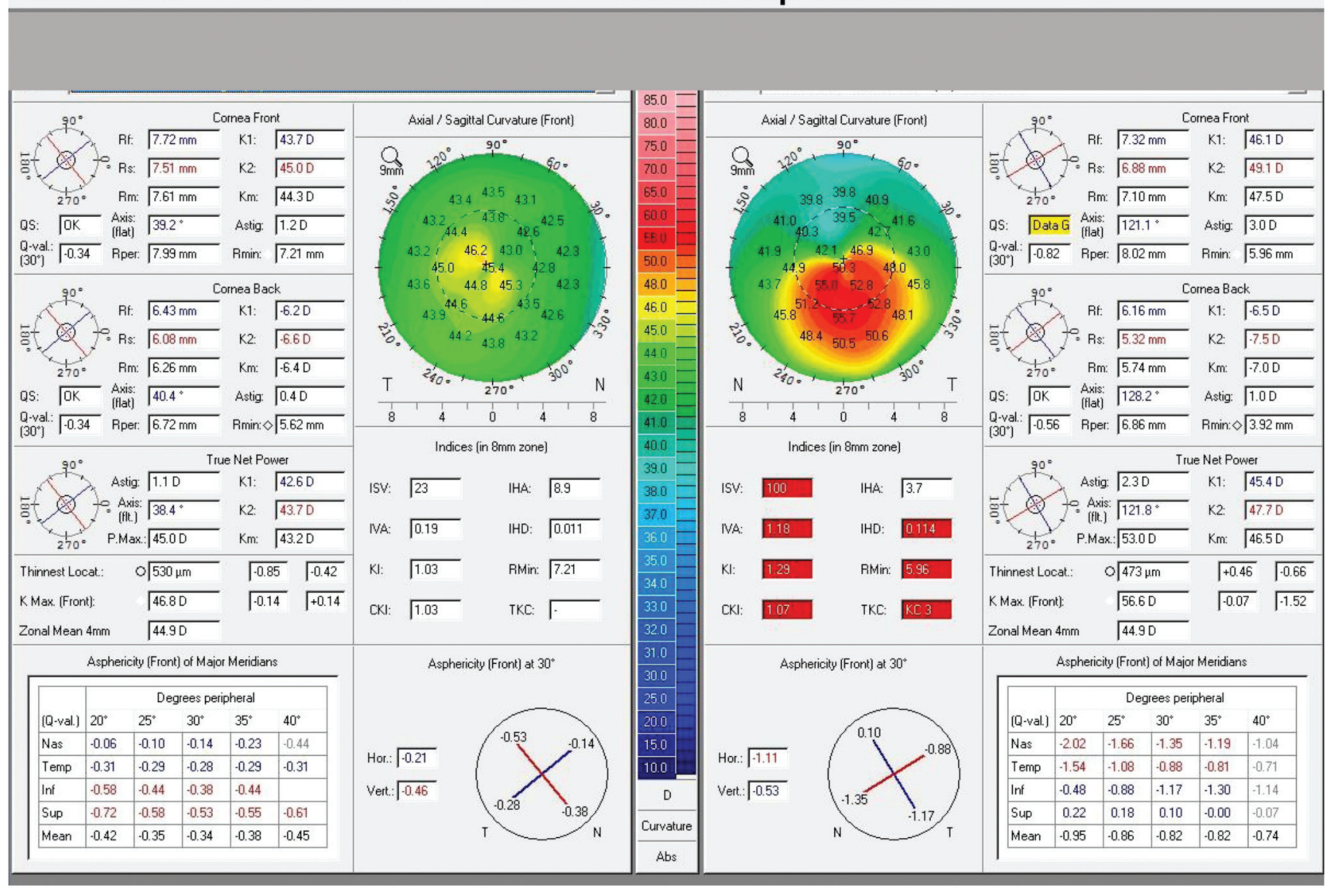

Figure A. Example of forme fruste keratoconus in the right eye. 
OCULUS - PENTACAM Show 2 Exams Topometric

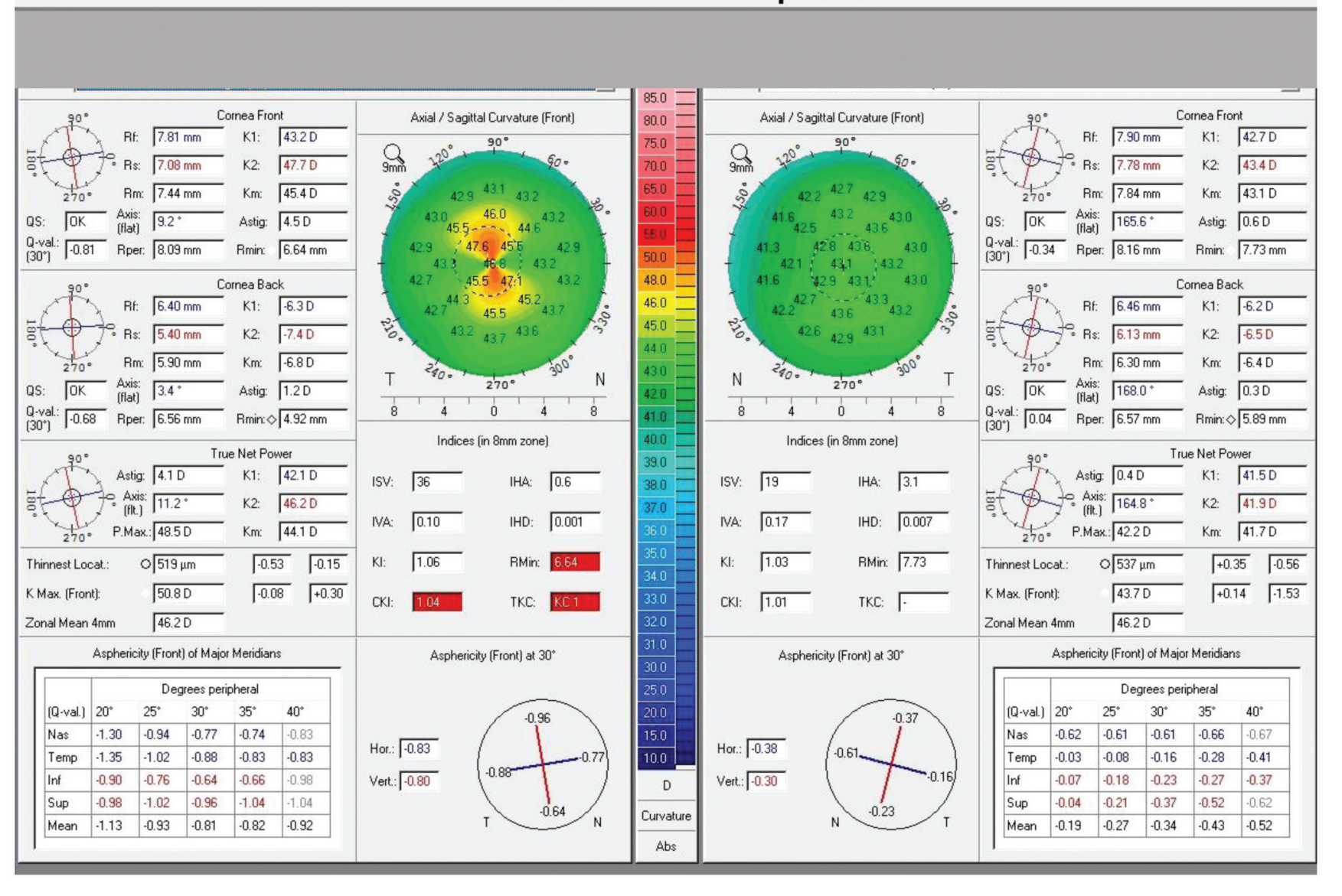

Figure B. Example of forme fruste keratoconus in the left eye. 


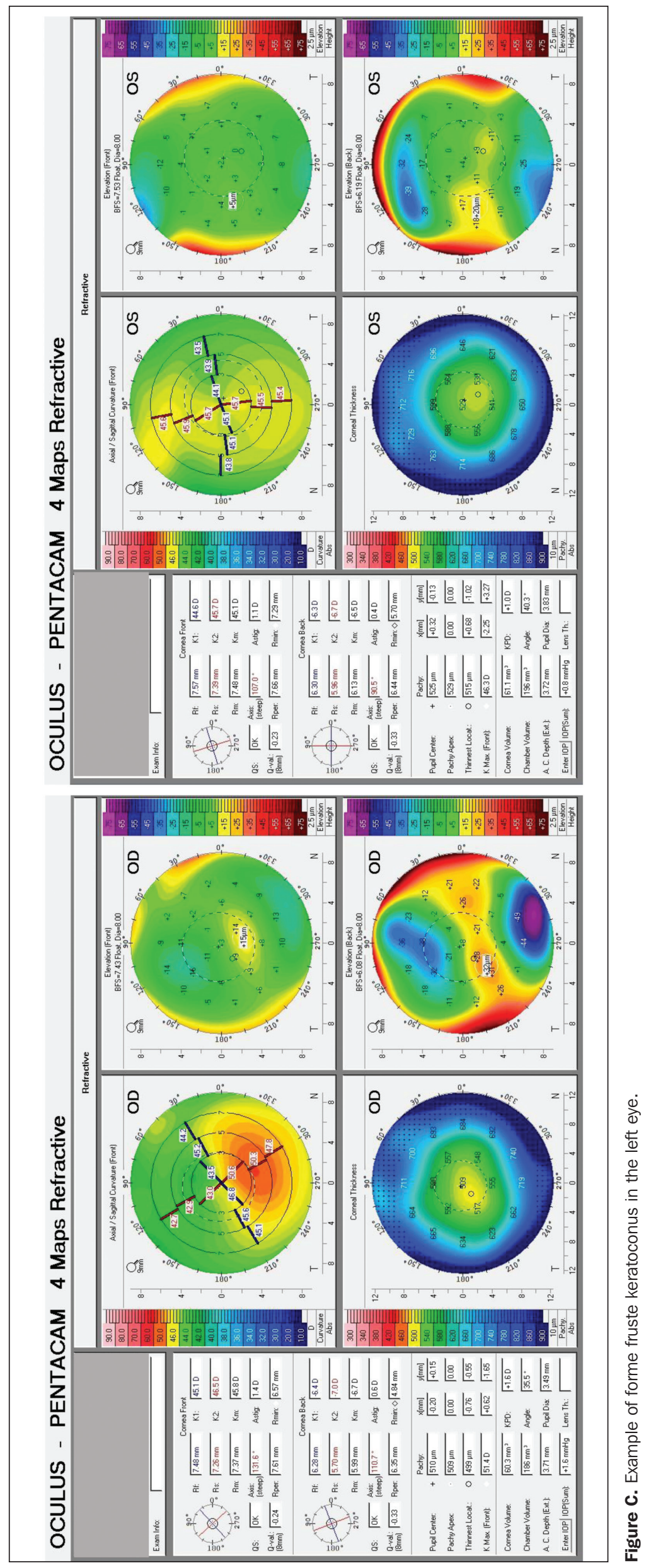




\begin{tabular}{|c|c|c|}
\hline \multicolumn{3}{|c|}{ Parameters From Corneal Tomography (Extracted From Oculus Pentacam HR) } \\
\hline Parameter & Operation Definition & Interpretation \\
\hline ISV & $\begin{array}{l}\text { Standard deviation of individual corneal sagittal } \\
\text { radii from the mean curvature }\end{array}$ & Expression of the corneal surface irregularity \\
\hline IVA & $\begin{array}{l}\text { Measurement of the mean difference between } \\
\text { superior and inferior corneal curvature }\end{array}$ & $\begin{array}{l}\text { The value of curvature symmetry, similar to commonly } \\
\text { used inferior/superior ratio }\end{array}$ \\
\hline IHD & $\begin{array}{l}\text { Decentration of elevation data in the vertical } \\
\text { direction }\end{array}$ & Provides the degree of decentration in the vertical direction \\
\hline Enhanced BFS front & Variable of the anterior corneal elevation & Enhanced anterior best fit sphere \\
\hline Enhanced BFS back & Variable of the posterior corneal elevation & Enhanced back best fit sphere \\
\hline Elevation B BFS Apex & Variable of the posterior corneal apex elevation & Best fit sphere posterior of the corneal apex \\
\hline Elevation B BFS Thinnest & $\begin{array}{l}\text { Variable of the posterior corneal thinnest point } \\
\text { elevation }\end{array}$ & Best fit sphere posterior of the corneal thinnest point \\
\hline $\begin{array}{l}\text { Elevation B BFS Max 4-mm } \\
\text { Zone }\end{array}$ & Variable of the posterior corneal elevation & $\begin{array}{l}\text { Best fit sphere of the posterior cornea outside } 4-\mathrm{mm} \\
\text { zone from thinnest point }\end{array}$ \\
\hline Elevation B BFTE Apex & Variable of the posterior corneal apex elevation & Best fit toric ellipsoid posterior of the corneal apex \\
\hline Elevation B BFTE Thinnest & $\begin{array}{l}\text { Variable of the posterior corneal thinnest point } \\
\text { elevation }\end{array}$ & Best fit toric ellipsoid posterior of the thinnest point \\
\hline $\begin{array}{l}\text { Elevation B BFTE Max 4-mm } \\
\text { Zone }\end{array}$ & Variable of the posterior corneal elevation & $\begin{array}{l}\text { Best fit toric ellipsoid of the posterior cornea outside } \\
\text { 4-mm zone from thinnest point }\end{array}$ \\
\hline BAD-D & Belin/Ambrósio display & $\begin{array}{l}\text { The } \mathrm{D} \text { values represent the mean deviation, representing } \\
\text { the pachymetric progression }\end{array}$ \\
\hline ART Max & Ambrósio relational thickness maximum & Division of the thinnest point by the RPI Maximum \\
\hline ART Average & Ambrósio relational thickness average & Division of the thinnest point by the RPI Average \\
\hline RPI Max & Relative pachymetric index maximum & $\begin{array}{l}\text { The value of pachymetric progression is calculated by } \\
\text { reference to the average curve. For each meridian, a } \\
\text { maximum value that expresses pachymetric progression } \\
\text { is calculated. }\end{array}$ \\
\hline RPI Average & Relative pachymetric index average & $\begin{array}{l}\text { The value of pachymetric progression is calculated by } \\
\text { reference to the average curve. For each meridian, a } \\
\text { maximum value that expresses pachymetric progression } \\
\text { is calculated. }\end{array}$ \\
\hline
\end{tabular}




\section{TABLE B}

\section{Variables Derived From the Signal of the Dynamic Bidirectional Applanation Device ${ }^{a}$}

\begin{tabular}{ll}
\hline Variable & \multicolumn{1}{c}{ Operation Definition } \\
\hline Group 1 & Peak intensity of first applanation event \\
A1 & Peak intensity of second applanation event \\
A2 & A2-A1 \\
Applanation peak difference & Minimum applanation intensity between A1 and \\
Concavity min & A2 \\
Concavity mean & Mean applanation intensity between A1 and A2
\end{tabular}

\section{Group 2}
Average P1P2
Pmax
$(\mathrm{P} 1+\mathrm{P} 2) / 2$
Peak value of pressure signal

\section{Group 3}

Concavity duration

Concavity time

Lag time

Applanation onset time

\section{Group 4}

Slope up

Slope down

\section{Group 5}

Hysteresis loop area

\section{Group 6}

Impulse

Time lapse between $\mathrm{A} 1$ and $\mathrm{A} 2$

Time from onset of applied pressure to A1

Time between Pmax and concavity min

Time from onset of applied pressure to A1

Positive slope of the first applanation peak, from inflection point to peak

Negative slope of the first applanation peak, from inflection point to peak

Area enclosure by pressure vs applanation function
Maximum surface area achieving planarity during inward deformation

Maximum surface area achieving planarity during recovery

Difference in maximum planarity between inward and recovery phases

Depth and irregularity (nonplanarity) of deformation

Depth and irregularity of deformation average

Average of the pressures at the 2 applanation events

Force and time required to reach first applanation event

Temporal delay of deformation recovery between applanation events

Time required to achieve maximum deformation from onset of impulse

Delay between peak applied pressure and maximum deformation

Time required to achieve first applanation from onset of impulse

Rate of achieving peak planarity

Rate of loss of peak planarity

Hysteresis aggregated over entire deformation cycle except concavity

Air pressure intensity

${ }^{a}$ Data adapted from Hallahan KM, Sinha Roy A, Ambrósio R Jr, Salomao M, Dupps WJ Jr. Discriminant value of custom ocular response analyzer waveform derivatives in keratoconus. Ophthalmology. 2014;121:459-468. 


\begin{tabular}{|c|c|c|c|c|c|c|c|}
\hline \multicolumn{8}{|c|}{$\begin{array}{l}\text { TABLE C } \\
\text { Comparison of AUROC, Select Parameter Cut-off, Sensitivity, and Specificity for } \\
\text { Variables Statistically Different Between Normal and FFKC Groups }\end{array}$} \\
\hline Parameter & AUROC & SEa & $P^{b}$ & Sensibility & Specificity & Cut-off & Cl 95\%c \\
\hline FECTB & 0.953 & 0.0237 & $<.0001$ & 85.71 & 98.68 & $>0.4653$ & 0.890 to 0.986 \\
\hline BAD-D & 0.91 & 0.05 & $<.0001$ & 90.48 & 82.89 & $>0.96$ & 0.835 to 0.959 \\
\hline B BFTE Th & 0.872 & 0.05 & $<.0001$ & 85.71 & 78.95 & $>0$ & 0.789 to 0.931 \\
\hline ART Maximum & 0.863 & 0.06 & $<.0001$ & 85.71 & 78.95 & $\leq 435$ & 0.778 to 0.924 \\
\hline RPI Maximum & 0.841 & 0.07 & $<.0001$ & 80.95 & 97.37 & $>1.29$ & 0.753 to 0.907 \\
\hline B BFS Th & 0.839 & 0.06 & $<.0001$ & 85.71 & 75 & $>3$ & 0.751 to 0.906 \\
\hline ART Average & 0.838 & 0.06 & $<.0001$ & 80.95 & 75 & $\leq 557$ & 0.749 to 0.905 \\
\hline RPI Average & 0.836 & 0.06 & $<.0001$ & 80.95 & 75 & $>0.95$ & 0.747 to 0.904 \\
\hline B BFTE $4 Z$ & 0.779 & 0.06 & $<.0001$ & 71.43 & 67.11 & $>7$ & 0.684 to 0.857 \\
\hline p1area1 & 0.717 & 0.07 & .0009 & 71.43 & 63.16 & $\leq 1,237.5$ & 0.617 to 0.804 \\
\hline p1area & 0.707 & 0.07 & .0014 & 66.67 & 65.79 & $\leq 2,885.188$ & 0.606 to 0.795 \\
\hline HLA & 0.688 & 0.07 & .0059 & 66.67 & 71.05 & $\leq 49.903$ & 0.586 to 0.778 \\
\hline h1 & 0.663 & 0.07 & .0213 & 61.9 & 68.42 & $\leq 319.688$ & 0.560 to 0.756 \\
\hline h11 & 0.663 & 0.07 & .0213 & 61.9 & 68.42 & $\leq 213.125$ & 0.560 to 0.756 \\
\hline Impulse & 0.650 & 0.07 & .0323 & 66.67 & 67.11 & $\leq 4,401.975$ & 0.546 to 0.744 \\
\hline dive1 & 0.649 & 0.07 & .0297 & 61.90 & 63.16 & $\leq 279$ & 0.545 to 0.743 \\
\hline Pmax & 0.648 & 0.07 & .0325 & 61.90 & 61.84 & $\leq 414$ & 0.544 to 0.742 \\
\hline BFS Fr & 0.646 & 0.07 & .0267 & 61.90 & 63.16 & $\leq 7.86$ & 0.542 to 0.740 \\
\hline B BFTE Ax & 0.645 & 0.08 & .0582 & 57.14 & 67.11 & $>-1$ & 0.541 to 0.739 \\
\hline Ele B BFS 8-mm Apex & 0.645 & 0.0764 & .0582 & 57.14 & 67.11 & $>1$ & 0.541 to 0.739 \\
\hline uslope2 & 0.642 & 0.08 & .0646 & 57.14 & 69.74 & $\leq 65.5$ & 0.538 to 0.736 \\
\hline aspect2 & 0.630 & 0.0809 & .1072 & 57.14 & 67.11 & $\leq 13.425$ & 0.526 to 0.726 \\
\hline slew2 & 0.629 & 0.08 & .1040 & 61.90 & 63.16 & $\leq 274.125$ & 0.525 to 0.725 \\
\hline h2 & 0.629 & 0.0796 & .1040 & 52.38 & 67.11 & $\leq 262.688$ & 0.525 to 0.725 \\
\hline h21 & 0.629 & 0.0796 & .1040 & 52.38 & 67.11 & $\leq 175.125$ & 0.525 to 0.725 \\
\hline uslope1 & 0.627 & 0.0753 & .0928 & 61.90 & 53.95 & $\leq 54.714$ & 0.522 to 0.723 \\
\hline CRF & 0.622 & 0.0742 & .1012 & 61.90 & 68.42 & $\leq 8.9$ & 0.517 to 0.718 \\
\hline dslope2 & 0.622 & 0.0830 & .1432 & 52.38 & 69.74 & $\leq 16.732$ & 0.517 to 0.718 \\
\hline mslew2 & 0.622 & 0.08 & .1432 & 61.90 & 52.63 & $\leq 20.733$ & 0.517 to 0.718 \\
\hline uslope21 & 0.622 & 0.0824 & .1402 & 52.38 & 75.00 & $\leq 46.583$ & 0.517 to 0.718 \\
\hline mslew1 & 0.622 & 0.0727 & .0930 & 57.14 & 64.47 & $\leq 89$ & 0.518 to 0.719 \\
\hline Aindex & 0.620 & 0.0738 & .1050 & 66.67 & 61.84 & $\leq 9.384$ & 0.515 to 0.716 \\
\hline A1 & 0.617 & 0.0750 & .1171 & 57.14 & 60.53 & $\leq 525$ & 0.513 to 0.714 \\
\hline aspect21 & 0.617 & 0.0752 & .1184 & 52.38 & 72.37 & $\leq 16.563$ & 0.513 to 0.714 \\
\hline aspect1 & 0.614 & 0.0729 & .1176 & 57.14 & 60.53 & $\leq 15.694$ & 0.510 to 0.711 \\
\hline w2 & 0.613 & 0.0811 & .1629 & 61.90 & 59.21 & $>19$ & 0.509 to 0.710 \\
\hline path1 & 0.610 & 0.0828 & .1830 & 52.38 & 67.11 & $>23.29$ & 0.506 to 0.708 \\
\hline Enh BFS Back $8 \mathrm{~mm}$ & 0.610 & 0.0689 & .1094 & 61.90 & 61.84 & $\leq 6.49$ & 0.506 to 0.708 \\
\hline $\mathrm{CH}$ & 0.607 & 0.0766 & .1633 & 57.14 & 51.32 & $\leq 9.9$ & 0.502 to 0.705 \\
\hline dslope21 & 0.604 & 0.0740 & .1598 & 61.90 & 52.63 & $\leq 30.65$ & 0.500 to 0.702 \\
\hline Slope down & 0.604 & 0.0742 & .1609 & 57.14 & 57.89 & $>-92.74853801$ & 0.500 to 0.702 \\
\hline
\end{tabular}




\begin{tabular}{|c|c|c|c|c|c|c|c|}
\hline \multicolumn{8}{|c|}{ 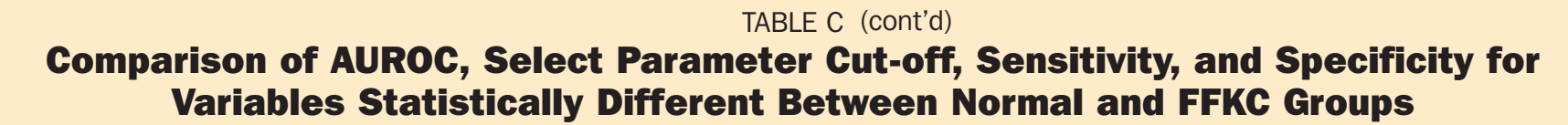 } \\
\hline Parameter & AUROC & $\mathrm{SE}^{\mathrm{a}}$ & $P^{b}$ & Sensibility & Specificity & Cut-off & Cl $95 \%$ c \\
\hline A2 & 0.601 & 0.0793 & .2033 & 61.90 & 60.53 & $\leq 457$ & 0.496 to 0.699 \\
\hline dslope1 & 0.599 & 0.0723 & .1711 & 66.67 & 48.68 & $\leq 26.393$ & 0.495 to 0.697 \\
\hline $\mathrm{IHD}$ & 0.599 & 0.0663 & .1369 & 57.14 & 67.11 & $>5$ & 0.494 to 0.697 \\
\hline p2area & 0.597 & 0.0755 & .1981 & 57.14 & 60.53 & $\leq 2,013$ & 0.493 to 0.695 \\
\hline Aplhf & 0.589 & 0.0702 & .2035 & 57.14 & 61.84 & $>1.3$ & 0.485 to 0.688 \\
\hline Applanation onset time & 0.588 & 0.0690 & .2022 & 66.67 & 50.00 & $\leq 7.65$ & 0.484 to 0.687 \\
\hline bindex & 0.587 & 0.0764 & .2545 & 52.38 & 59.21 & $\leq 9.656$ & 0.483 to 0.686 \\
\hline Concavity min & 0.586 & 0.0800 & .2798 & 61.90 & 55.26 & > 48.33333333 & 0.482 to 0.686 \\
\hline w11 & 0.585 & 0.0788 & .2834 & 47.62 & 63.16 & $\leq 10$ & 0.480 to 0.684 \\
\hline AvgP1P2 & 0.584 & 0.0725 & .2486 & 57.14 & 51.32 & $\leq 172.5$ & 0.479 to 0.683 \\
\hline Slope up & 0.580 & 0.0779 & .3070 & 61.90 & 44.74 & $\leq 77.84313725$ & 0.475 to 0.679 \\
\hline Concavity mean & 0.570 & 0.0831 & .3982 & 52.38 & 57.89 & $\leq 113.0817204$ & 0.466 to 0.670 \\
\hline p2area1 & 0.566 & 0.0730 & .3631 & 57.14 & 55.26 & $\leq 884.5$ & 0.462 to 0.667 \\
\hline path21 & 0.564 & 0.0721 & .3756 & 61.90 & 47.37 & $\leq 35.025$ & 0.459 to 0.664 \\
\hline w21 & 0.559 & 0.0738 & .4275 & 57.14 & 44.74 & $>8$ & 0.454 to 0.659 \\
\hline slew1 & 0.558 & 0.0762 & .4445 & 61.90 & 53.95 & $\leq 56.357$ & 0.454 to 0.659 \\
\hline uslope11 & 0.557 & 0.0790 & .4705 & 52.38 & 46.05 & $\leq 57$ & 0.453 to 0.658 \\
\hline ISV & 0.555 & 0.0669 & .4149 & 61.90 & 52.63 & $\leq 19$ & 0.450 to 0.655 \\
\hline $\begin{array}{l}\text { Ele B BFS 8-mm max } \\
4-m m \text { zone }\end{array}$ & 0.554 & 0.0746 & .4729 & 52.38 & 59.21 & $>13$ & 0.449 to 0.655 \\
\hline dive2 & 0.554 & 0.0830 & .5136 & 57.14 & 46.05 & $\leq 230.75$ & 0.450 to 0.655 \\
\hline aspect11 & 0.540 & 0.0860 & .6411 & 61.90 & 46.05 & $\leq 23.778$ & 0.436 to 0.642 \\
\hline aspect11 & 0.540 & 0.0860 & .6411 & 52.38 & 52.63 & $\leq 22.693$ & 0.436 to 0.642 \\
\hline IVA & 0.533 & 0.0718 & .6467 & 47.62 & 51.32 & $\leq 0.16$ & 0.429 to 0.635 \\
\hline w1 & 0.530 & 0.0735 & .6822 & 61.90 & 51.32 & $\leq 21$ & 0.426 to 0.632 \\
\hline Concavity time & 0.529 & 0.0720 & .6856 & 57.14 & 50.00 & $\leq 12.975$ & 0.425 to 0.631 \\
\hline Lag time & 0.522 & 0.0684 & .7449 & 52.38 & 46.05 & $\leq .675$ & 0.418 to 0.625 \\
\hline path2 & 0.505 & 0.0736 & .9457 & 42.86 & 46.05 & $\leq 25.232$ & 0.402 to 0.608 \\
\hline Applanation peak dif & 0.505 & 0.0823 & .9544 & 57.14 & 52.63 & $\leq-112$ & 0.401 to 0.608 \\
\hline Concavity duration & 0.501 & 0.0767 & .9935 & 52.38 & 43.42 & $>10.8$ & 0.397 to 0.604 \\
\hline dslope11 & 0.501 & 0.0814 & .9877 & 47.62 & 44.74 & $>35.208$ & 0.398 to 0.604 \\
\hline \multicolumn{8}{|c|}{ 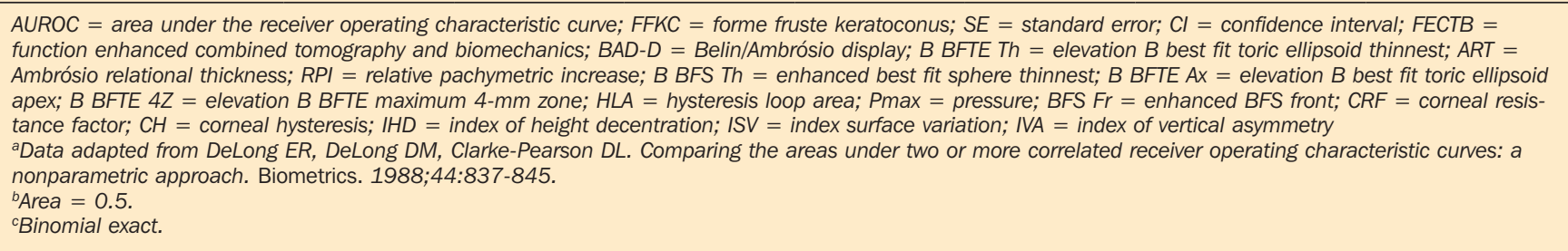 } \\
\hline
\end{tabular}




\section{TABLE D}

Comparison of All ORA Variables

\begin{tabular}{|c|c|c|c|}
\hline Parameter & Normal Group Mean \pm SD (Range) & FFKC Group Mean \pm SD (Range) & $\mathbf{P a}^{\mathbf{a}}$ \\
\hline p1area1 & $1,412.29 \pm 447.54$ (554.25 to $2,686.5)$ & $1,085.19 \pm 363.43$ (553.5 to $1,762.38$ ) & $.0024^{b}$ \\
\hline p1area & $3,331.25 \pm 910.23(1,402$ to $5,606.06)$ & $2,644.83 \pm 746.93(1,450.13$ to 4,008$)$ & $.0037^{\mathrm{b}}$ \\
\hline HLA & $5,501.00 \pm 15,339.15(8,853$ to 97,693$)$ & $43,614.55 \pm 18,597.56(-11,656.5$ to 78,052$)$ & $.0086^{\mathrm{b}}$ \\
\hline h1 & $377.05 \pm 103.64$ (218.62 to 640.87$)$ & $319.06 \pm 102.74$ (168.75 to 563.62$)$ & $.0228^{b}$ \\
\hline h11 & $251.37 \pm 69.09(145.75$ to 427.25$)$ & $212.70 \pm 68.49$ (112.5 to 375.35$)$ & $.0228^{b}$ \\
\hline Impulse & $4,536.22 \pm 323.30(3,775.35$ to $5,314.08)$ & $4,402.86 \pm 418.84(3,796.58$ to $5,807.36)$ & .0363 \\
\hline dive1 & $323.77 \pm 117.79$ (38.75 to 614.5$)$ & $266.39 \pm 115.82(19.5$ to 561.75$)$ & .0375 \\
\hline Pmax & $423.74 \pm 35.49$ (344 to 505$)$ & $408.43 \pm 45.09$ (348 to 557$)$ & .0391 \\
\hline mslew2 & $127.75 \pm 56.57$ (25.75 to 326$)$ & $97.08 \pm 51.35$ (19.25 to 173$)$ & .0421 \\
\hline uslope2 & $85.99 \pm 43.24$ (14.67 to 239.12$)$ & $62.14 \pm 45.55$ (3.27 to 138.75$)$ & .0478 \\
\hline slew2 & $86.40 \pm 42.63$ (17.5 to 239.12$)$ & $63.70 \pm 44.10(6.66$ to 138.75$)$ & .0487 \\
\hline aspect11 & $24.42 \pm 9.85$ (10.11 to 55.70$)$ & $25.29 \pm 16.21$ (9.37 to 75.15$)$ & .5751 \\
\hline aspect2 & $18.15 \pm 8.99(4.62$ to 55.02$)$ & $14.54 \pm 11.03(1.76$ to 42.44$)$ & .0685 \\
\hline h2 & $304.57 \pm 90.38(153.56$ to 605.25$)$ & $252.13 \pm 120.12(72.18$ to 466.87$)$ & .0705 \\
\hline h21 & $203.04 \pm 60.25(102.37$ to 403.5$)$ & $168.09 \pm 80.08(48.12$ to 311.25$)$ & .0705 \\
\hline uslope1 & $63.29 \pm 31.77$ (23.22 to 187.16$)$ & $49.71 \pm 25.17$ (18.13 to 112.35$)$ & .0768 \\
\hline mslew1 & $106.28 \pm 39.59$ (53.5 to 239.5$)$ & $89.58 \pm 30.31$ (40.75 to 163.25$)$ & .0876 \\
\hline CRF & $9.75 \pm 1.78(6$ to 148$)$ & $9.10 \pm 1.99(5$ to 13.8$)$ & .0893 \\
\hline dslope2 & $23.63 \pm 12.93(5.58$ to 83.21$)$ & $19.51 \pm 14.99(2.58$ to 57.71$)$ & .0893 \\
\hline uslope21 & $68.73 \pm 31.87$ (13.91 to 157$)$ & $54.66 \pm 42.13$ (1.73 to 137.62$)$ & .0893 \\
\hline Aindex & $9.24 \pm 1.05$ (5.34 to 10$)$ & $8.59 \pm 1.52(4.95$ to 10$)$ & .0943 \\
\hline A1 & $582.36 \pm 148.06$ (358 to 916$)$ & $519.00 \pm 160.57$ (279 to 860$)$ & .1005 \\
\hline aspect21 & $26.23 \pm 14.16$ (4.56 to 69.9$)$ & $20.85 \pm 15.21$ (2.18 to 62.25$)$ & .1005 \\
\hline aspect1 & $17.98 \pm 6.19$ (8.33 to 39.31$)$ & $15.34 \pm 6.19(6.75$ to 31.31$)$ & .1109 \\
\hline w2 & $18.58 \pm 4.57$ (10 to 34$)$ & $22.67 \pm 9.02(11$ to 42$)$ & .1139 \\
\hline path1 & $22.45 \pm 3.98$ (15.29 to 36.43$)$ & $24.96 \pm 6.05$ (16.18 to 36.43$)$ & .1232 \\
\hline $\mathrm{CH}$ & $10.15 \pm 1.62(6.2$ to 14.1$)$ & $9.27 \pm 2.16(6$ to 13.1$)$ & .1353 \\
\hline dslope21 & $40.85 \pm 26.15$ (5.79 to 135.12$)$ & $32.25 \pm 24.35$ (3.30 to 104.87 ) & .1459 \\
\hline Slope down & $-105.20 \pm 36.41(-249.56$ to -55.47$)$ & $-93.03 \pm 38.26(-181.99$ to -40.32$)$ & .1459 \\
\hline A2 & $476.96 \pm 128.73(256$ to 807$)$ & $418.38 \pm 174.69$ (141 to 737$)$ & .1585 \\
\hline dslope1 & $26.06 \pm 8.89$ (11.60 to 52.81$)$ & $23.25 \pm 9.42(9.85$ to 45.1$)$ & .1664 \\
\hline p2area & $2,183.22 \pm 550.90(1,163.43$ to $3,829.81)$ & $1,928.98 \pm 597.38$ (447.5 to $2,909.63)$ & .1746 \\
\hline Aplhf & $1.32 \pm 0.31(0.8$ to 2.4$)$ & $1.55 \pm 0.84(0.9$ to 5$)$ & .212 \\
\hline Applanation onset time & $7.69 \pm 0.43(6.6$ to 8.6$)$ & $7.66 \pm 0.77$ (6.75 to 10.65$)$ & .2185 \\
\hline bindex & $9.34 \pm 1.08$ (4.90 to 10$)$ & $8.42 \pm 2.32(1.80$ to 10$)$ & .2234 \\
\hline Concavity min & $48.84 \pm 9.88(15.33$ to 78.33$)$ & $51.87 \pm 12.44$ (23.66 to 167.33$)$ & .2268 \\
\hline w11 & $11.00 \pm 2.45(5$ to 17$)$ & $10.05 \pm 3.25(5$ to 16$)$ & .237 \\
\hline AvgP1P2 & $176.00 \pm 22.23(129$ to 235.5$)$ & $179.43 \pm 55.85$ (140.5 to 411.5$)$ & .2423 \\
\hline Slope up & $76.83 \pm 25.59$ (33.70 to 148.92$)$ & $66.57 \pm 30.08(17.26$ to 121$)$ & .266 \\
\hline Concavity mean & $119.83 \pm 21.32$ (81.88 to 185.03$)$ & $117.94 \pm 44.04$ (71.91 to 279.63$)$ & .3266 \\
\hline p2area1 & $927.63 \pm 274.63(486$ to 1,868$)$ & $831.18 \pm 277.80$ (206.5 to $1,316.5)$ & .3532 \\
\hline path21 & $36.04 \pm 9.34$ (14.58 to 66.56$)$ & $34.00 \pm 8.43(21.34$ to 52.54$)$ & .3716 \\
\hline w21 & $9.01 \pm 3.05$ (4 to 23 ) & $10.67 \pm 5.31(5$ to 24$)$ & .4128 \\
\hline slew1 & $64.82 \pm 31.25$ (19.37 to 187.16$)$ & $56.41 \pm 25.13$ (19.5 to 112.35$)$ & .4153 \\
\hline uslope11 & $62.02 \pm 31.59$ (14.5 to 181.37$)$ & $56.78 \pm 31.67$ (13.83 to $1,443.37)$ & .4254 \\
\hline dive2 & $235.69 \pm 84.44(87.5$ to 551.25$)$ & $209.27 \pm 111.58(20$ to 409$)$ & .4487 \\
\hline
\end{tabular}




\section{TABLE D (cont'd)}

\section{Comparison of All ORA Variables}

\begin{tabular}{|c|c|c|c|}
\hline Parameter & Normal Group Mean \pm SD (Range) & FFKC Group Mean \pm SD (Range) & $P^{\mathbf{a}}$ \\
\hline aspect11 & $24.42 \pm 9.85$ (10.11 to 55.70$)$ & $25.29 \pm 16.21$ (9.37 to 75.15$)$ & .5751 \\
\hline w1 & $21.57 \pm 2.70(15$ to 28$)$ & $21.71 \pm 3.51$ (17 to 31$)$ & .6742 \\
\hline Concavity time & $12.92 \pm 0.86$ (10.42 to 14.62$)$ & $12.83 \pm 0.87$ (11.1 to 14.4$)$ & .6838 \\
\hline Lag time & $0.79 \pm 0.55(0.1$ to 2.32$)$ & $0.74 \pm 0.50$ (0.075 to 2.25$)$ & .7558 \\
\hline path2 & $25.61 \pm 6.63(11.57$ to 51.14$)$ & $25.33 \pm 6.05$ (15.28 to 36.86$)$ & .9441 \\
\hline Applanation peak dif & $-105.39 \pm 126.27(-433$ to 168$)$ & $-100.62 \pm 169.75(-353$ to 199$)$ & .9476 \\
\hline dslope11 & $40.62 \pm 17.45$ (14.10 to 104.06$)$ & $44.78 \pm 27.95(1,434$ to 121.62$)$ & .986 \\
\hline Concavity duration & $10.91 \pm 0.45$ (9.9 to 12.15$)$ & $10.69 \pm 1.14$ (6.15 to 11.625$)$ & .993 \\
\hline
\end{tabular}

ORA = Ocular Response Analyzer (Reichert Ophthalmic Instruments, Depew, NY); SD = standard deviation; FFKC = forme fruste keratoconus; HLA = hysteresis loop area; Pmax = pressure; $\mathrm{CRF}=$ corneal resistance factor; $\mathrm{CH}=$ corneal hysteresis

aMann-Whitney U test.

${ }^{b}$ Statistically significant difference after Bonferroni correction. 